\title{
A MORALIZAÇÃO DO CLERO CASTELHANO NO SÉCULO XIII
}

Andréia Cristina Lopes Frazão da Silva*

SINTESE - O IV Concilio de Latrão, realizado em 1215, foi para a Igreja Ocidental o mais importante do periodo medieval. Seus 70 cânones apresentam uma síntese do projeto de reforma eclesial liderado pelo Papado, em vias de implantação desde meados do século XI, e que visava, dentre outros pontos, a moralização do clero. Contudo, qual foi o impacto destas regulamentações canônicas nas diversas regiōes da Cristandade?

Como tentativa de resposta parcial a tais questões, optamos por um estudo de caso: o da Igreja Castelana, tão resistente às imposiçōes romanas no século XI. Para o estudo da questão, optamos pela análise da obra literária Vida de Santo Domingo de Silos, de. Gonzalo de Berceo, clérigo secular e primeiro autor culto a escrever em castelhano do qual possuímos notícias históricas. Objetivamos, através do estudo comparativo desta obra literária e os cânones do Concilio de 1215, o impacto e penetração no inicio do século XIII, em Castela, do projeto de reformulação da moral eclesiástica promovido pelo papado.
ABSTRACT - The IV council of Latran, which took place in 1215 , was the most important one for the occidental Church, during the medieval period. Its 70 canons present a synthesis of the project of ecclesiastical reformation, leaded by the papacy, which was going to be implanted since the middle of the XI century, which aimed at, among other points, the moralization of the clergy. Nevertheless, what was the impact of those canonical regulations among the various regions of the Christendom?

As a partial attempt to answer those questions, we opted for a case study: the Castillian Church, very resisting to the Roman impositions in the XI century. To study the matter, we opted for the analysis of the Vida de Santo Domingo de Silos, from Gonzalo de Berceo, centenary clergyman, and first cult author to write in castillian, of which we have historical background. Our objective, through the comparative study of this book, and also the canons of the council of 1215 , is the impact and clearsightedness of the project of reformation of the ecclesiastical morality, promoted by the papacy in the beginning of the XIII century, in Castela.

$O$ objetivo do presente trabalho é discutir o alcance do projeto papal de moralização do clero no seio da igreja castelhana, no século XIII. Consideramos que esta busca pela moralização do clero católico é fruto de um sistema ético ${ }^{1}$ elaborado

- Universidade Federal do Rio de Janeiro - UFRJ.

1 Entendemos por sistema ético um conjunto de normas e atitudes morais que possuem uma base filosófica, isto é, que sejam explicadas racionalmente, ainda que através do discurso teológico. FERRATER MORA, J. Diccionario de Filosofia del Bolsillo. 3ed. Madrid: Alianza, 1989, p. 278; LEGRAND, G. Dicionánio de Filosofia. Lisboa: Ediçōes 70, 1983, p. 270.

\begin{tabular}{|l|l|l|l|l|l|}
\hline VERTTAS & Por to Alegre & v. 40 & $\mathrm{n}^{2} 159$ & Setembro 1995 & p. 559-576 \\
\hline
\end{tabular}


pela igreja de Roma como um dos fundamentos da Reforma Gregoriana ${ }^{2}$ e que se encontra sintetizado nos cânones do IV Concílio de Latrão.

Os estudos sobre a Península Ibérica durante a Idade Média encontram-se em plena renovação. ${ }^{3}$ Ampliou-se o repertório de fontes ainda pouco exploradas, desenvolveram-se trabalhos interdisciplinares e vem se afirmando uma nova tendência historiográfica: a dos trabalhos de micro-história.

Entretanto, às temáticas relacionadas à religião e à religiosidade, com exceção dos trabalhos sobre a Inquisição, ainda não foram suficientemente explorados pelos pesquisadores e, como constata Peter Linehan, ainda há muito o que fazer. ${ }^{4} \mathrm{O}$ presente trabalho, ainda que breve e introdutório, pretende ser uma contribuição neste sentido, suscitando questionamentos.

Nosso trabalho será apresentado em dois blocos. No primeiro, nos deteremos no estudo das linhas gerais da Reforma Eclesiástica promovida pelo Papado e o papel da moralização do clero neste quadro. Concentrar-nos-emos na análise dos cânones do IV Concílio de Latrão, desvelando o modelo ideal de clérigo desejado pela Igreja Romana.

No segundo bloco, faremos um estudo sobre a igreja castelhana no século XIII, em geral, e a obra Vida de St. Domingo de Silos de Gonzalo de Berceo em particular, visando discutir a presença dos princípios éticos requeridos por Roma em meio ao corpo eclesiástico do Reino de Castela.

A opção pelo estudo desta obra repousa em alguns dados. Primeiramente, por ser Gonzalo de Berceo o primeiro poeta a escrever em castelhano do qual possuimos noticias seguras, ainda que escassas. Sabemos que viveu na primeira metade do século XIII, na região de La Rioja, foi criado em um mosteiro e era clérigo secular.

Este último dado nos é fundamental, pois partimos do pressuposto de que uma obra literária não deve ser compreendida somente à luz da inspiração de seu autor, mas sim como o produto da leitura do mundo social, da intertextualidade e dos interesses de seu grupo. ${ }^{5}$ Optamos, portanto, pelo estudo de uma obra literária, pois acreditamos, como afirma Gonzalez Minguez:

2 Em nosso trabalho faremos uma distinção entre Reforma Eclesiástica e Reforma Gregoriana. Entendemos como Reforma Eclesiástica ao amplo movimento de reformulação da igreja que integrou vários projetos diferentes íniciado no Império Carolíngio. Ainda que estes projetos mantivessem alguns pontos em comum, diferenciavam-se quanto aos objetivos e estratégias. A Reforma Gregoriana era um desses projetos. Desenvolvida a partir dos projetos de Reforma anteriores - seculares e monásticos - independiza-se e sob a liderança do papado propōe a centralização institucional e jurídica da igreja. MITRE FERNÁNDEZ, E. "Concilios y teocracia pontificia". In: ARRANZ, A. Los Concilios Medievales. Madrid: Historia 16, 1985, p. 16; FRANK, I. W. Historia de la Iglesia Medieval. Barcelona: Herder, 1989, p. 91; GARCIA VILLOSLADA, R. (org.) Historia de la Iglesia Española. Madrid: BAC, 1982. Tomo 2: Edad Media, p. 259 ss.

3 VICENT, B. Espanha. In: BURGUIÉRE, A. Dicionário das Ciências Histónicas. Rio de Janeiro: Imago, 1993, p. 298-303; RUCQUOI, A. Histoire Médievale de la Péninsule Ibérique. Paris: Éditions du Seuil, 1993, p. 9.

4 LINEHAN, P. La Iglesia Española y el Papado en el siglo XIII. Salamanca: Universidad Pontificia, 1975, p. xviii.

5 CHARTIER, R. A História Cultural: entre práticas e répresentações. Rio de Janeiro: Difel, 1990, p. 17. 
"[...] tanto el arte como la literatura, en cuanto son instrumentos que reflejan una concreta concepción del mundo y de los sistemas de valores que rigen la sociedad en un determinado momento, constituyen fuentes esenciales para la Historia [.... $]^{16}$

Nossa investigação, ainda que pautada em um estudo de caso, visto que privilegia uma única obra literária castelhana, preocupa-se em verificar como Gonzalo de Berceo, enquanto representante do clero castelhano, apreendeu o projeto de moralização proposto pelo papado.

Para tanto, objetivamos contrapor o modelo ideal de clérigo presente nesta obra literária com o presente nos cânones do IV Concilio de Latrão. Para reconstruir o modelo ideal de clérigo presente nas fontes escolhidas, optamos por analisar os textos nos detendo unicamente no nível da semântica discursiva, pois acreditamos que este nos revela os fenômenos ideológicos, entendidos aqui como a visão de mundo partilihada por um grupo social, presentes nas formações discursivas. ${ }^{\text {? }}$ Interessa-nos detectar que adjetivos e ações são associadas aos clérigos em ambos os textos como elementos semânticos reveladores do sistema ético subjacente às fontes.

Neste trabalho, para a compreensão dos fenômenos históricos, privilegiamos o estudo das representações ideológicas, dotando-as de certa autonomia, porém em relação dialética com as estruturas materiais. ${ }^{8}$

\section{1 - A Reforma Eclesiástica e o IV Concílio de Latrão}

A Igreja Cristã, durante a Alta Idade Média, sofreu inúmeras mudanças, adaptando-se às novas estruturas sociais, econômicas, políticas e mentais da Europa Ocidental. As comunidades cristãs ruralizaram-se, perderam o seu caráter comunitário, tornaram-se alvo da influência da aristocracia laica e dos poderes seculares. A Igreja tornou-se uma "federação" de episcopados e mosteiros, onde as práticas simoníacas e o nicolaísmo eram constantes. ${ }^{9}$

A partir do século IX, frente às novas transformações estruturais que se processavam no ocidente, foram surgindo inúmeros projetos que visavam umà Reforma Eclesiástica. Tais movimentos, desenvolvidos nos diversos setores da sociedade medieval, portavam concepções e objetivos diferentes quanto ao corpo eclesial. ${ }^{10}$

Dentre as inúmeras propostas de Reforma, desejamos destacar algumas. Primeiramente, as de iniciativa dos poderes seculares, pautadas nas Teorias do Monismo Teocrático, onde "... el sacerdócio se subordina inequivocamente a la monarquia", ${ }^{11}$ ou do Dualismo Teocrático, que reconhecendo a existência de dois poderes - o regnum e o sacerdotium - propõem um projeto de sociedade no qual "...al po-

6 GONZALEZ MINGUEZ, C. "Sobre Arte, Literatura e História de las Mentalidades". In: —_ (ed.) La Otra Historia: Sociedad, Cultura y Mentalidades. Bilbao: Universidad del país Vasco, 1993, p. 15.

7 FIORIN, J. L. Elementos de Análise do discurso. 3. ed. São Paulo: Contexto, 1992, p. 63 ss; BARROS, D. L. P. de Teoria Semiótica do Texto. São Paulo: Ática, 1990, p. 68 ss.

8 VOVELLE, M. Ideologias e mentalidades. São Paulq: Brasiliense, 1988.

9 FRANK; I. W., op. cit., p. 31 a 39.

10 Ver nota 2.

11 FRANK, I. W., op. cit., p. 83. 
der regio le correspondia un caráter sagrado, el sacerdocio podía participar del poder real". ${ }^{12}$

Em segundo lugar, as de origem monástica, onde a Ordem de Cluny é o grande destaque. A luta contra a intervenção laica, a busca por uma renovação dos costumes e pela unidade litúrgica foram alguns dos princípios deste projeto de Reforma, que através da fundação e vinculação de inúmeros mosteiros se expandiu por várias regiões da Europa. ${ }^{13}$

As propostas de Reforma de caráter popular também não podem ser esquecidas. Como a Pataria Milanesa, que utilizando-se inclusive da força, propunha uma transformação radical das estruturas sociais e a eliminação dos clérigos considerados indignos. ${ }^{14}$

De todos os projetos de Reforma Eclesiástica surgidos na Europa nos séculos $\mathrm{IX}$ ao XI, o que nos interessa especialmente é o proposto pelos bispos de Roma, conhecido como Reforma Gregoriana. Este repousava nos seguintes pontos: organização e centralização de toda a hierarquia clerical tendo à liderança o pontífice romano, a luta contra a intervenção laica na Igreja, a moralização do clero e a catolicalização da sociedade.

Iniciada em meados do século XI, a Reforma Gregoriana teve seu ponto culminante no início do século XIII sob o pontificado de Inocêncio III, quando foi realizado o maior concílio ecumênico medieval: o IV Concilio de Latrão.

Este projeto de reforma só pode ser compreendido à luz da mentalidade feudal. Fundamentou-se em uma releitura do Dualismo Político, pautado na autonomia e superioridade do sacerdotium frente ào regnum et imperium, e no poder jurisdicional do papa, calcado no princípio petrinoapostólico.

$\mathrm{O}$ poder reivindicado pelo papa era de caráter universal, respaldado pela hierarquia eclesiástica. Ao afirmar-se como portador de toda auctoritas sacra, o papado vê o seu papel como o de um grande suserano entre todos os outros suseranos seculares.

A organização e centralização de todo o corpo eclesiástico tendo como ponto central o Papa, como portador da plenitude potestas, visava, portanto, o fortalecimento e a independência da Igreja. Como ressalta Jürgen Miethke:

"La confrontación entre el papado y el poder temporal hizo que la Iglesia y los expertos en
derecho canónico elaboraran cada vez más cuidadosamente una teoria acerca de la organiza-
ción de la Iglesia como corporación, acerca de la distribución de responsabilidades dentro de
ella y del alcance de la obediencia pretendida por la cúpula eclesiástica."15

A busca por uma disciplina moral rigorosa e universal no seio da Igreja é uma das diversas faces deste projeto que objetivava fundamentar a unidade da fé cristã sob a liderança papal e assegurar o seu espaço no conflito de poderes que marcaram a história da Europa durante a Baixa Idade Média.

12 Op. cit. acima, p. 87.

13 PAUL, J. La Iglesia y la cultura en Occidente (siglos IX-XII). Barcelona: Labor, 1988. v. 1: "La santificación del orden temporal y espiritual", p. 148 a 176.

14 FERNÁNDEZ CONDE, F. J. et al. Las herejías medievales. Madrid: Historia 16, 1985, p. 5-6; MTRE FERNÁNDEZ, E. op. cit., p. 15.

15 MIETHKE, J. Las ideas politicas de la Edad Media. Buenos Aires: Biblos, 1993, p. 71. 
A fim de propagar e introduzir os principios da Reforma Gregoriana, o Papado lançou mão de alguns instrumentos: regulamentou a eleição do papa através do Colégio de Cardeais; enviou legados como seus representantes diretos para introduzir a reforma em diversas regiōes; passou a confirmar a eleição dos arcebispos; fundou cortes eclessiásticas para tratar não somente de problemas eclesiais, mas também os de caráter moral, casamentos e heranças; ampliou e reformulou o Direito Canônico; passou a convocar os Concílios Universais e organizou a corte papal. ${ }^{16}$

Para aprofundarmos o estudo das concepções morais requeridas aos clérigos pela Reforma Gregoriana, nos deteremos a seguir, conforme já assinalamos, na análise dos cânones do IV Concílio de Latrão.

O IV Concilio de Latrão foi convocado pelo papa Inocêncio III através da bula Vineam Domini Sabaoth de 10 de abril de 1213. Foram convidados a participar deste concílio não somente os líderes eclesiásticos regulares e seculares, como também autoridades laicas. ${ }^{17}$ Conforme assinala a bula convocatória, 0 objetivo da reunião era "...promover a reconquista da Terra Santa e a Reforma da Igreja Universal" [grifo meu]. ${ }^{18}$

Em $1^{\circ}$ de novembro de 1215 iniciou-se o IV Concilio de Latrão com a presença de cerca de 1.200 pessoas, representando mais de 80 províncias eclesiásticas, não só do Ocidente, mas também da Europa Central e Oriental. ${ }^{19} \mathrm{O}$ Concilio contou ainda com a presença de autoridades laicas da Sicilia, Constantinopla, França, Inglaterra, Hungria, Jerusalém, Chipre e Aragão. ${ }^{20}$

Durante o Concilio foram realizadas três sessões plenárias, além de cerimônias litúrgicas de caráter popular. ${ }^{21}$ Deste concílio resultaram 70 cânones, cujas atas originais não foram preservadas. Possuimos uma cópia de 1216, que foi tomada como texto de autoridade e incluida no Corpo de Direito Canônico. ${ }^{22}$

Segundo Jane Sayers, "Those who took the decisions at the Fourth Lateran Council were a very small group of cardinals close to the pope and, an occasion, the pope himself alone". ${ }^{23}$ Esta opinião é partilhada por Brenda Bolton que afirma que "o texto era redigido na Cúria... as constitutiones domini papae foram lidas e aprovadas, e nem sequer foram debatidas no Concílio". ${ }^{24}$

Quando nos detemos no exame dos cânones conciliares e verificamos o seu caráter normativo, unidade orgânica e as temáticas abordadas, concordamos com

16 FOREVILLE, R. Lateranense I, II, III. Vitoria: Eset 1972, p. 18; MOORE, R. I. La formación de una sociedad represora. Poder y disidencia en la Europa Occidental. 950-1250. Barcelona: Critica, 1989; MITRE FERNÁNDEZ, E., op. cit., p. 16; FRANK, I. W. op. cit., p. 96 e 97.

17 FOREVILLE, R. Lateranense IV. Vitoria: Eset, 1973, p. 34.

18 Bula convocatória do IV concilio de Latrão Vineam Domini Sabaoth apud FOREVILLE, R. Lateranense $I V . . .$, p. 139.

19 FOREVILLE, R. Lateranense $I V \ldots$, p. 43.

20 SAYERS, J. Innocent III. Leader of Europe 1198-1216. London: Longman, 1994, p. 96.

21 FOREVILLE, R. Lateranense $I V$..., p. 55 a 68.

22 Sobre os manuscritos e transmissão dos cânones do IV Concilio de Latrão ver FOREVILLE, R. Lateranense IV., op. cit. Em nosso trabalho utilizamos as duas únicas ediçōes críticas da obra: a já citada edição de FOREVILLE, R. e a de HEFELE - LECLERO. Histoire des conciles. Paris: s/ed, 1913. T 5, p. 1316 a 1398. Optamos por traduzir as transcriçöes dos cânones inseridas no texto.

BOLTON, B. op. cit., p. 127. 
Sayers e Bolton. Esta legislação é produto de um grupo de juristas, conhecedores do direito canônico e romano, comprometidos com a política eclesiástica do papado.

Os cânones de 1215 abordam questões quanto às heresias, o governo eclesiástico, a correção dos costumes, a formação dos clérigos, o ministério pastoral, os sacramentos, o casamento e os excluídos - judeus e muçulmanos.

Concentrar-nos-emos no estudo dos cânones 14, 15, 16, 17, 18, 19, 63, 64, 65 e 66 que tratam especificamente da moral clerical. Porém, como o discurso ético é um dos fundamentos da Reforma Eclesiástica promovida por Roma, encontramos nos demais cânones referências a atitudes e comportamentos esperados pelos clérigos. Faremos referências a estes somente a título de complementação.

O cânone 14 inicia-se com uma exortação "no tocante aos costumes e à conduta dos clérigos". Estes devem "esforçar-se" para "viver em continência e castidade", principalmente os que se encontram "nas ordens sagradas". O objetivo é "não atrair do céu a cólera divina. "Devem" servir a Deus com o coração puro e o corpo limpo". Caso pequem, "gravemente ou não", devem ser castigados pois "...já que o temor de Deus não chega a preservá-los do pecado, ao menos a pena temporal possa conseguir este fim".

Segundo o cânone 15, os clérigos devem "abster-se, com grande cuidado, do uso da bebida e da embriaguez". Há uma explicação para tal cuidado, pois "a embriaguez faz perder o espírito e acende as paixões carnais". Por este cânone fica proibido a todos os clérigos a "montaria e caça de aves", bem como a "criação de cães e falcões "para este fim.

"Os clérigos não podem exercer cargos seculares nem administrar assuntos temporais, sobretudo se são desonestos". Assim é iniciado o cânone 16. Este cânone acrescenta que os clérigos "não devem assistir a sessões de pantomimas, juglares ou atores"; "que se abstenham de visitar tabernas ou hospedarias, a não ser em caso de viagem", "não joguem os dados nem as tabas e tampouco sejam espectadores de tais jogos"; "devem levar tonsura apropriada"; "dedicar-se aos cultos divinos e a estudos honestos".

Neste cânone há ainda uma descrição detalhada sobre as vestes clericais. Estas não devem ser "nem demasiado curtas nem demasiado longas"; "os vestidos externos devem ser mantidos fechados", "não devem usar tecidos de cor vermelha ou verde, nem luvas ou sapatos bordados ou qualquer outro tipo de ornamento". Este cânone procura alertar aos clérigos que estes devem ser diferentes dos laicos não só no interior mas na aparência exterior e por suas ações.

O cânone 17 inicia-se constatando que muitos clérigos passam grande parte da noite em festas ostentosas e em conversas indecorosas, passando a dormir durante o dia, deixando de celebrar ou assistir à missa. Proíbe, sob pena de excomunhão, estes abusos e outros similares e ordena, "em virtude da obediência, que os clérigos tomem parte na celebração do ofício divino, tanto de dia quanto de noite".

A proibição aos clérigos de participar em duelos, ditar ou efetuar sentenças de morte são o objeto do cânone 18. O alvo desta resolução são as ordálias e as justiças particulares, que desafiavam a justiça papal. Porém, o cânone acrescenta que os clérigos devem abster-se de exercer cargos ou profissões que impliquem em derramamento de sangue. 
A preocupação do cânone 19 é o cuidado para com o patrimônio eclesiástico, que é um dos deveres dos clérigos. Estes devem dedicar-se a cuidar dos vasos sagrados, lugares de culto e vestimentas litúrgicas, mantendo-os limpos. É perceptível nesta legislação o cuidado em manter uma clara distinção entre os bens da igreja e os pessoais do clero, principalmente através da proibição destes depositarem nas igrejas seus objetos pessoais, salvo em caso de guerra, incêndios ou em situações de extrema necessidade.

Os cânones de 63 a 66 tratam da simonia entre o clero secular e regular, não se limitando a condenar a venda de cargos eclesiásticos, mas denunciando e criticando todas as práticas religiosas que acabam sendo mediadas pelo dinheiro. No cânone 63 é reafirmado o objetivo do papado de "desarraigar um abuso tão manifesto, um costume que seria melhor denominado de corrupção".

As práticas simoniacas entre monges e monjas que, sob pretexto de pobreza. dos mosteiros, limitam o ingresso de pessoas que não possuem dinheiro é o tema do cânone 64. Já nos cânones 65 e 66 é condenada a prática da venda de sepulturas cristãs, do ingresso em ordens religiosas, da bênção dos esposos e "outras práticas parecidas". No cânone 66 chega a afirmar-se que por avareza, muitos clérigos "fingem maliciosamente impedimentos inexistentes". O castigo será "restituir em dobro a cobrança injusta, dedicando este valor integralmente em benefício das igrejas prejudicadas por estas práticas injustas". ${ }^{25}$

Encontramos nos cânones dedicados à heresia e à pastoral inúmeras outras recomendações quanto à moral clerical.

No cânone 3, Sobre os hereges, há uma longa exposição sobre como os clérigos deveriam se portar perante a heresia, conforme o esperado pela igreja romana. Em primeiro lugar, não devem acatar as doutrinas heréticas, antes devem resistir a elas e combatê-las. Seu dever é entregar os hereges às autoridades seculares, ainda que sejam clérigos, e excomungar não só os que seguem a heresias, mas também aqueles que os recebem, ajudam e defendem, negando-lhes os sacramentos e sepultura cristã e refutando suas esmolas e ofertas.

$\mathrm{O}$ cânone ainda acrescenta que cabe às autoridades episcopais zelar para que nas regiões sob sua jurisdição a heresia não se desenvolva. Para tanto, devem visitá-las, investigando, buscando e condenando os hereges. Se for negligente nesta função, "...será destituído do cargo episcopal e será substituído por uma pessoa idônea, disposta a confundir a heresia".

Nas resoluções do IV Concilio de Latrão é evidente a preocupação romana com a evangelização, entendida aqui como a inserção da Igreja na sociedade. Para tanto, institui a confissão e a comunhão anual, regulamenta o casamento e requer o pagamento dos dízimos.

O cuidado pastoral é delegado aos clérigos, que tem como uma de suas funções primordiais zelar pela "saúde do povo cristão", ${ }^{26}$ através "da palavra e do exemplo". ${ }^{27}$

25 Cânone 65.

26 Cânone 10.

27 Cânone 10. 
Para cumprir com tais responsabilidades, os clérigos devem não somente viver irrepreensivelmente, mas também conhecer as Escrituras e tudo o que for relacionado ao ministério pastoral. Instruir gratuitamente aos clérigos mais pobres passa a ser uma tarefa dos clérigos da catedral e obter a instrução, a dos clérigos das paróquias. $^{28}$

A preocupação do papado com a moral clerical pode ser explicada por alguns fatores. Em primeiro lugar, responder aos novos anseios espirituais dos laicos, relacionados ao crescimento da Europa. Em segundo lugar, resistir aos diversos grupos heréticos, portadores de projetos de Reforma Eclesial onde o respeito, a submissão e obediência à Igreja eram questionados. Em terceiro, eliminar a influência secular junto à hierarquia, principalmente no tocante à simonia e às rendas eclesiásticas. Em quarto lugar, assegurar a preservação do patrimônio eclesiástico, ameaçado pelo nicolaísmo bem como pelas já citadas práticas simoníacas. E, finalmente, ampliar a influência e presença da Igreja romana no seio da sociedade.

A moral requerida por Roma e presente nos cânones acima assinalados repousa em alguns princípios teológicos que foram desvelados em nossa análise. São estes princípios teológicos que explicam e justificam as normas e atitudes morais propostas pelo papado, organizando-as em um sistema ético.

O primeiro princípio é a negação do mundo e de suas paixões. Enquanto cristäos especiais, que viviam para servir a Deus, os clérigos deveriam manter um comportamento que os distinguisse dos laicos, tornando-se o seu exemplo. Como o sacerdotium era o representante maior da ordem divina na terra, cabia ao corpo eclesiástico, através da pureza moral, refletir a glória celeste no mundo terrestre, guiando, através da palavra e da vida irrepreensivel, ao povo cristão.

Em segundo lugar numa Eclesiologia. A Igreja era vista como a esposa pura de Cristo. A relação de Cristo e a Igreja, no simbolismo do esposo e esposa, deveria aplicar-se também aos sacerdotes individuais em relação às suas comunidades. Assim como Cristo deu-se pela Igreja, os clérigos deveriam sufocar suas paixões para melhor atender suas comunidades.

Ainda que, como afirma Jacques Paul, "es en el terreno moral en que las ideas gregorianas guardan estrecha relación con la tradición reformista anterior" ${ }^{29}$ este sistema ético, à luz do projeto de Reforma Gregoriana, ganha um novo sentido: o ideal da libertas Ecclesiae, isto é, a busca pela independência jurídica e institucional da Igreja sob a liderança papal e de sua preeminência sobre os poderes seculares.

\section{2 - A Igreja castelhana no século XIII, Gonzalo de Berceo e a Vida de St. Domingo de Silos}

Até meados do século XI a igreja castelhana manteve-se isolada do restante da Europa. Diversos fatores explicam este fenômeno, principalmente a expansão muçulmana na Península Ibérica, a Reconquista e a permanência de traços da reli-

29 PAUL, J., op. cit., p. 213. 
giosidade romano-visigótica, como, por exemplo, na liturgia e na organização da vida regular. $^{30}$

Segundo Sanchez Herrero esta igreja encontrava-se "...en manos de los laicos, ...con las dióceses ...escasamente organizadas, ...con un contenido doctrinal escasamente desarollado....". ${ }^{31}$

A Reforma Eclesiástica em Castela, iniciada com o Concílio de Coyanza de 1055, foi inicialmente patrocinada pelo Rei, tendo como ponto de partida as tradições da Igreja Visigótica. ${ }^{32}$

Os pontos básicos desta Reforma foram a restauração, fundação e organização interna das dioceses; a aproximação com a Cristandade do restante da Europa através do Caminho de Santiago, da introdução da Regra Beneditina e da instalação da Ordem de Cluny que, como vimos na primeira parte do trabalho, também possuia um projeto de Reforma Eclesiástica e a diminuição da influência laica.

Entretanto, o principal instrumento na quebra do particularismo da igreja castelhana e de sua reformulação foi a Reforma Gregoriana. ${ }^{33}$

Apesar dos contatos mantidos com Roma desde o século VIII, através de cartas e legados papais, a igreja castelhana mantinha-se, ainda no século XI, à margem da liderança da Igreja Romana. Foi a partir de Gregório VII que ampliaram-se as relações entre esta igreja e o papado através de um incremento do intercâmbio epistolar e do envio de um maior número de legados. ${ }^{34}$

A introdução da Reforma Gregoriana em Castela visou, em um primeiro momento, a abolição da liturgia moçárabe e a introdução da liturgia romana, o fortalecimento da hierarquia episcopal sob a hegemonia do pontífice e o reconhecimento da soberania do papa sobre os territórios reconquistados dos muçulmanos.

Apesar do sucesso aparente, visto que a Igreja Castelhana no século XII adotara a liturgia romana e a hierarquia episcopal encontrava-se fortalecida sob a aceitação da hegemonia papal, ainda no século XIII não se encontrava totalmente reformada. Era visivel o declínio das ordens monásticas, o crescente regalismo, o bajxo grau de instrução e do nível moral do clero. ${ }^{35}$

As primeiras décadas do século XIII foram marcadas pelo avanço da Reconquista e da afirmação do Reino de Castela como hegemônico na Península Ibérica, sob apoio papal.

30 SANCHEZ HERRERO, J. Iglesia y Religiosidad. In: ORTZ DE VILLAJOS, S. de M., LADERO QUESADA, M. A. (coord.) Historia general de España y America. Madrid: Rialph, 1984. T 4: La España de los cinco reinos (1085-1369), GARCIA VILLOSLADA, R., op. cit.

31

32

33

34

35

SANCHEZ HERRERO, J., op. cit., p. 342.

Ibidem.

VALDEÓN, J. et al. Feudalismo y consolidación de los pueblos hispânicos (Siglos XI-XV). Barcelona: Labor, 1980, p. 80.

GARCIA VILLOSLADA, R., op. cit., p. 259 a 260.

Sobre a igreja castelhana no século XIII ver MANSILLA REOYO, D. Iglesia Castelhano Leonesa y curia romana en los tiempos del rey San Fernando. Madrid: CSIC, 1945. Do mesmo autor ver o artigo Inocencio III y los reinos hispânos. Anthologia Annua. 1954, 2, p. 9 a 49. Ver também LINEHAN, P., op. cit. e as obras das notas 30,33 e 34 . 
Após a batalha de Navas de Tolosa (1212), onde participaram juntos todos os reis da Península Ibérica, o papado passou a favorecer as iniciativas de Reconquista particulares de cada reino, permitindo que parte das rendas eclesiásticas fossem utilizadas para financiar as campanhas. Como afirma Demetrio Mansilla:

"...los papas procurarán conceder a los cruzados españoles las mismas gracias que a los que luchen en los Santos Lugares y hacer que a los monarcas respectivos no les falten medios económicos necesarios para la realización de sus objetivos" ${ }^{36}$.

A Reconquista ampliou os limites do Reino de Castela. Muitas terras foram entregues às Ordens Militares e a alguns clérigos ligados à coroa, dentre estes o bispo de Toledo. Porém, nem toda a Igreja Castelhana foi beneficiada igualmente, ainda que tenha participado do financiamento da expansão. Este quadro acabou gerando, entre outros fatores, uma grave crise econômica, acentuada após o IV Concilio de Latrão, a partir do qual as rendas eclesiásticas castelhanas passaram a sustentar não só a cruzada peninsular, mas também a oriental.

A crise econômica vivida pela Igreja Castelhana, a presença de prelados identificados com os projetos politicos do Reino de Castela e as constantes intervenções de Fernando III em questões eclesiásticas comprovam que a Igreja Castelhana do século XIII não se encontrava reformulada sob o controle de Roma.

Para fazer frente a esta situação, o Papado preocupou-se em introduzir as resoluções do IV Concílio de Latrão no seio desta igreja. Foram enviados legados papais a Castela com o objetivo de adaptar os cânones de 1215 à realidade da região.

Em todo o século XIII a Igreja Castelhana reuniu-se unicamente em cinco concilios provinciais preocupados especificamente em reformular esta igreja aos moldes dos cânones do IV Concilio de Latrão. Este desinteresse, segundo Peter Linehan, é fruto do espirito de Reconquista que marcou toda a história do Reino de Castela e que se manifestou no desprezo pela autoridade distante, visando a manutenção de sua identidade. ${ }^{37}$

Entretanto, até que ponto a resistência dos clérigos castelhanos ao projeto de moralização proposto pelo Papado e sintetizado nọs cânones do çoncilio de 1215 foi total? Qual foi o alcance, em Castela, do sistema ético proposto por Roma?

Para a responder a tais questões, como já ressaltamos acima, nos deteremos em um estudo de caso: a análise da obra Vida de St. Domingo de Silos.

Gonzalo de Berceo, autor da obra em análise, nasceu por volta de $1196 \mathrm{em}$ uma localidade próxima ao Mosteiro de San Millan de la Cogolla, um dos mais importantes da região de La Rioja ${ }^{38}$ e onde, segundo nos informa em uma de suas obras, fora criado. ${ }^{39}$

La Rioja foi durante a Idade Média uma verdadeira encruzilhada de culturas e influências. Pertenceu ao Islão e somente no X sua reconquista foi se tornando efetiva. Devido a sua localização entre os Reinos de Navarra, Castela e Aragão, foi

36 Inocencio III y los reinos hispânos., op. cit., p. 10.

37 LINEHAN, P., op. cit., p. 2.

38 Sobre La Rioja na Idade Média ver R. DE LAMA, I. R. Colección Diplomática de La Rioja, Logroño: Instituto de Estudios Riojanos, 1979. T 1: Estudio.

39

Vida de San Millan de la Cogolla 489 c. 
palco de constantes disputas territoriais até ser incorporada definitivamente a Castela em $1176 .^{40}$

A presença do Caminho de Santiago na região levou ao desenvolvimento do comércio, da manufatura e da vida urbana. Pela rota chegaram inúmeros estrangeiIOS, trazendo "novidades " do restante da Europa e rompendo com o isolamento da Península. ${ }^{41}$

Graças a alguns documentos preservados, nos quais figura como testemunha, sabemos que Gonzalo era clérigo secular em Berceo, localidade onde nasceu e de onde vem o nome pelo qual é conhecido. ${ }^{42}$

Como clérigo de La Rioja, Gonzalo de Berceo estava subordinado ao bispado de Calahorra. Este, apesar de estar localizado geograficamente no Reino de Castela, e portanto sujeito a intervenções políticas do Reino e Igreja castelhanas, era sufragâneo em questões eclesiais da Província Eclesiástica Tarraconensis, seguindo a tradição da organização da igreja visigoda. ${ }^{43}$

Estes dados são fundamentais para reconstruirmos o lugar social de Berceo como clérigo. Apesar de ter mantido estreitas ligações com a vida monástica, foi ordenado clérigo secular. Como tal, pertencia ao clero castelhano mas encontravase subordinado às diretrizes eclesiais da Província Tarraconensis, que parecia estar mais atenta aos interesses do papado.

Enquanto a quase totalidade das dioceses da Igreja Castelhana, sob o governo do bispo de Toledo, voltava-se para a Reconquista, a Província Tarraconensis, que abrangia as dioceses mais orientais da Península Ibérica e incorporava as igrejas aragonesa e navarra, preocupou-se em introduzir os cânones do IV Concilio de Latrão nestas regiões, realizando cerca de 26 concilios provinciais durante o século XIII unicamente com este objetivo. ${ }^{44}$

Berceo escreveu 12 obras, todas sobre temas religiosos. Foram três hinos, três obras marianas, duas obras de caráter doutrinal e quatro obras hagiográficas. ${ }^{45}$ Todas estas obras foram redigidas a partir de fontes latinas e em castelhano, ainda que mantendo alguns traços do navarro e do aragonês, o que pode ser explicado pela idiossincrasia da região de La Rioja.

Encontram-se organizadas em forma de poesia, em coplas de quatro versos em caderna via, isto é, com catorze silabas, derivada dos versos alexandrinos utilizados pelos cantores de gesta franceses no século XII. Nos poemas de Berceo há uma

40 Garcia Turza, F. J. Morfologia de la ciudad de Nájera en la Edad Media. In: IGLESIA DUARTE, I. F. (org.) III Semana de Estudias Medievales. Logroño: Instituto de Estudios Riojanos, 1993, p. 74.

Sobre as peregrinaçōes a Santiago de Compostela há uma extensa bibliografia. Limitar-nos-emos a citar uma obra clássica que na edição facsímel de 1993 traz uma bibliografia completa e atualizada sobre a questão. VAZOUÉZZ DE PARGA, L., LACARRA, J. M., URIA RIU, J. Las peregrinaciones a Santiago de Compostela. Navarra: Gobiemo de Navarra, 1993.

43 ver VAZOUÉZ DE PARGA, L. La división de Wamba. Contribuición al estudio de la Historia y Geografia Eclesiástica de la Edad Media Española. Madrid: s/ed, 1943.

45 GONZALO DE BERCEO. Obra Completa. Organizada por Isabel Úria. Madrid: Espasa - Calpe, 1992. 
preocupação especial às rimas e ao ritmo das estrofes, estão povoadas de termos latinos e abundam as técnicas e os topoi retirados da literatura clássica. ${ }^{46}$

Pelas características de suas obras, Gonzalo de Berceo é considerado um poeta culto, participante do movimento literário denominado de Mester de Clerecia, nascido no século XIII em Castela em oposição à poesia popular dos juglares. ${ }^{47}$ Alguns autores chegam a afirmar que este autor provavelmente estudou na nascente Universidade de Palência, onde teria entrado em contato com a métrica francesa. ${ }^{48}$

Pela forma como Berceo narra suas estórias e dirige-se constantemente ao seu público como ouvintes, acredita-se que estas foram redigidas para serem recitadas em dias festivos e domingos, para uma platéia variada. ${ }^{49}$

De todas as obras de Berceo, optamos por analisar a Vida de St. Domingo de Silos por ser a única a retratar a vida de um clérigo. É importante ressaltar que o poeta não se preocupou em redigir uma biografia no sentido moderno, mas sim uma vida de santo, uma das muitas manifestações da literatura hagiográfica medieval. ${ }^{50}$

Este tipo de literatura nasceu no IV século, sendo cultivada durante toda a Idade Média. Seu objetivo era edificar os cristãos através do relato das virtudes e milagres daqueles que se destacavam por sua piedade. As vidas, portanto, se distanciam da biografia e da historiografia pois sua preocupação primordial não era relatar o que passou, mas apresentar as manifestações divinas realizadas através dos homens santos.

Ainda que resultantes, em muitos casos, de um longo processo de elaboração e transmissão oral e coletiva, as vidas de santos foram sendo fixadas, no Ocidente, principalmente por clérigos regulares e em latim, visando a produção de textos para uso litúrgico ou leitura privada.

A partir do século XIII, muitas dessas Vitae Latinii foram traduzidas e adaptadas para as línguas vernáculas. Dentre os muitos autores que se dedicaram a esta tarefa, encontramos, em Castela, Gonzalo de Berceo.

46 ARTILES, J. Los recursos literarios de Berceo. 2 ed. Madrid: Gredos, 1968; ALONSO, D. "Berceo y los topoi". In: - De los siglos oscuros al de Oro. 2 ed. Madrid: Gredos, 1964, p. 74 a 85; GIMENEZ RESANO, G. El mester poético de Gonzalo de Berceo. Logroño: Instituto de Estudios Riojanos, 1976; SALA, R. La lengua y el estilo de Gonzalo de Berceo. Logroño: Instituto de Estudios Riojanos, 1993.

47 Sobre a literatura castelhana no século XIII ver LOPEZ ESTRADA, F. Introducción a la literatura medieval española. 5 ed. Madrid: Gredos, 1987; LUIS MARTIN et all. Así nació el castellano. Madrid: Historia 16, 1985; DEYERMOND, A. D. Historia de la literatura española. 14 ed. Barcelona: Ariel, 1991. V 1: Edad Media.

48 DUTTON, B. Gonzalo de Berceo: unos datos biográficos. In: PIERCE, F., JONES, C. A. (eds.) Actas del Primer Congreso Intemacional de Hispanistas. Oxford: Dolphin BooKs, 1964, p. 249 a 254.

49 GYBBON - MONYPENNY, G. "The spanish mester de clerecia and its intended public: concerning the vality as evidence of passages of direct adress to audience." In: Medieval Miscellany presented to Eugéne Venaver, 1965.

50 Sobre a literatura hagiográfica ver CERTEAU, M. de. Uma variante: a edificação hagiografica. In: - A Escrita da História. Rio de Janeiro: Forense, 1982, p. 266 a 278; DUBOIS, J. LEMAITRE, J. L. Sources et Méthodes de I' hagiographie médiévale. Paris: CERF, 1993. LE GOFF, J et all. Hagiographie, Cultures et Sociétés. IV-XII. Actas del Colloque organisé a Nanterre et a Panis 2- 5 mai 1979. Paris: Etudes Augustiennes, 1981. 
A obra que iremos analisar retrata a vida, os milagres e a morte gloriosa de Santo Domingo, ${ }^{51}$ venerado como santo confessor e restaurador do mosteiro de Silos. Era natural de Cañas, pueblo de La Rioja, e viveu no século XI.

Foi ordenado sacerdote ainda bem jovem. Viveu como eremita durante algum tempo, sendo posteriormente admitido no Mosteiro de San Millan de la Cogolla como monge, chegando a prior em Santa Maria de Cañas, mosteiro vinculado a San Millan. Entretanto, após conflitos com o monarca Garcia de Navarra, que neste momento reinava em La Rioja, exilou-se em Castela sendo nomeado pelo Rei Fernando I abade do Mosteiro de São Sebastião de Silos, com o objetivo de restaurálo.

A Vida de St. Domingo de Silos foi a segunda obra escrita por Gonzalo de Berceo por volta de 1236. Foi transmitida por três manuscritos: o S, do século XIII; os $\mathrm{H}$ e $\mathrm{E}$ do século XIV. ${ }^{52}$ Acredita-se que o $\mathrm{H}$ é cópia direta de um dos manuscritos do autor. A obra latina Vita Dominici Silensis do monge de Silos Grimaldus, redigida no final do século XI, foi sua principal fonte. ${ }^{53}$

O poema em estudo encontra-se organizado em 777 coplas, divididas em três partes, denominadas nos manuscritos como livros. No primeiro é apresentada a formação do santo e suas obras como clérigo. Este é o que mais nos interessa, visto que é uma sintese biográfica. No segundo são apresentados seus milagres, sua morte e sua glorificação celeste. E, no terceiro, seus milagres póstumos.

Provavelmente eram gastas cerca de três horas para que todo o poema fosse recitado, o que explica o caráter didático da obra. Ao final de cada livro ou início do seguinte é apresentada uma breve recapitulação do já relatado. ${ }^{54}$ Há inúmeras referências à paisagem de La Rioja e seus costumes, ${ }^{55}$ além de toques de ironia ${ }^{56}$ crítica social, ${ }^{57}$ fórmulas épicas, ${ }^{58}$ além dos constantes diálogos com os ouvintes. ${ }^{59}$

Como St. Domingo é apresentado por Gonzalo de Berceo? Para reconstruirmos o retrato que Berceo traça do santo, seguiremos a ordem de sua narrativa.

Após indicar o propósito de sua obra e apresentar os pais de Santo Domingo, Berceo passa a enumerar suas virtudes. Ainda menino, antes mesmo de ser orde-

51 Sobre a biografia de Santo Domingo de Silos ver LABARTA CHAVES, T. Perfil histónico de Santo Domingo Manso. In: GONZALO DE BERCEO. Vida de Santo Domingo de Silos. 3 ed. Madrid: Castalia, 1987.

52 Sobre os manuscritos desta obra ver livros das notas 45 e 51, além de GIMÉNEZZ RESANO, G., op. cit. acima, SALA, R., op. cit. e a edição das Obras Completas de Berceo organizada por Brian Dutton. GONZALO DE BERCEO. Obras completas. London: Tamesis Books, 1978. T 4: La Vida de Santo Domingo de Silos.

53 GRIMALDO. Vita Dominici Siliensis. Estudo, edição crítica e tradução Vitalino Valcarcel. Logroño: Instituto de Estudios Riojanos, 1982.

54 Utilizaremos a sigla VSD para nos referirmos à obra em questão nas notas. VSD 288-289, 533-537, 754-758.

55 VSD 24, 69, 229-231, 266, 613, 734.

56 VSD $370,382,481-484,743$.

57 VSD 58.

58 VSD 700-703, 736-738.

59 VSD $2,8,33,71,73,109,113,171,227,291,315,335-336,375-376,609,617,644,676,751-752,757$, 759,775 . 
nado clérigo, servia aos seus pais com vontade e humildade. Este dado é ressaltado na obra, mais de uma vez:

"Servié a los parientes de toda voluntad: mostrava contra ellos toda umilidad

... traié, manguer niñuello, tan gran simplicidad

que se maravillaba toda la vecinidad. ${ }^{00}$

maguer de pocos dias, era muy mesurado,

de grandes e de chicos era mucho amado. ${ }^{61}$

Segundo o poema, St. Domingo não se interessava por jogos, nem estava atento a sua prática. ${ }^{62}$ Tampouco era avarento pois "el pan que... li davan los parientes... partiélo con los moços. ${ }^{63}$ Procurava evitar os risos, ${ }^{64}$ falar ou estar atento a coisas pouco edificantes:

"Traié en contra tierra los ojos bien premidos, por no catar follías teniélos bien nodridos, los labros de la boca teniélos bien cosidos, por non decir follias nin dichos corrompidos. ${ }^{.65}$

Berceo apresenta uma explicação para vida tão correta: "...lo iva guiando el Rey de Majestad... por essi condimiento vinié tan alumbrado... siempre es bien apreso qui de Dios es amado". ${ }^{66}$ As virtudes que abundavam na vida de St Domingo eram vistas, portanto, como fruto de seu relacionamento com Deus, que o ensinava, mas também de sua própria disposição em aprender:

"Si oié raçon buena, bien la sabié tener,

recordávale siempre, non la querié perder;"

Dentre os conhecimentos que detinha o santo encontravam-se o Pater Noster e o Credo in Deum, dentre muitas outras orações. ${ }^{ø 8} \mathrm{~A}$ instrução recebida por St Domingo é ainda ressaltada nas coplas 34 a 39 que retratam o séu ingresso na vida religiosa.

Segundo Berceo, quando St. Domingo decidiu ser clérigo, seus pais "...buscáronli maestro, el mejor que pudieron" ${ }^{\Perp \oplus}$ a fim de prepará-lo para a vida religiosa. É interessante verificar o quanto a obra procura realçar a necessidade da preparação intelectual para o exercício da função clerical.

$\mathrm{O}$ interesse do santo por aprender foi destacado na copla 37:

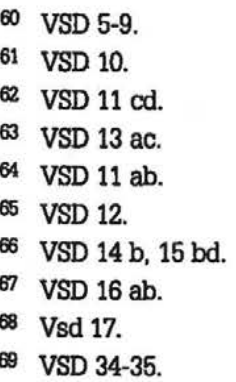


"Vinié a su escola el infant grand mañana, non avié e decírgelo nin padre nin ermana; non facié entre dia luenga meridiana, ovo algo apreso la primera semana."

A obra ressalta ainda que o santo aprendeu de memória os hinos e cânticos do ofício divino, além de conhecer a Escritura. Dentre as habilidades que desenvolveu estavam a leitura em voz alta e o conhecimento da música litúrgica. ${ }^{70}$

Por suas qualidades - instrução, disciplina e pureza - St. Domingo foi ordenado, pelo bispo de sua diocese, sacerdote em Cañas. ${ }^{71}$ Antes, porém, trilhou todos os graus menores:

"Tal era como plata, moço quatrogradero;

la plata tornó oro quando fue pistolero.

el oro, margarita en evangelistero,

quando subió a preste semejó al lucero. ${ }^{72}$

Em sua obra, Berceo procura ressaltar o papel pastoral do corpo eclesiástico quando afirma que "...obispos e abades quantos han dignidad, / pastores son clamados sobre la christiandad"73 demonstrando que o cuidado com a "saúde do povo cristão ${ }^{474}$ era uma das preocupações de St. Domingo:

"Castigava los pueblos, el padre ementado, acordava las yentes, partiélas de pecado, en visitar enfermos non era embargado, si podié fer almosna faziéla de buen grado. ${ }^{.75}$

Segundo o poema, foi motivado por viver sempre em maior pureza que St Domingo decidiu tornar-se eremita e afastar-se do seculum. ${ }^{76}$ Berceo justifica este ato traçando um paralelo entre a opção deste e de muitos outros cristãos "...que de Sancta Eglesia fueron cimentadores", ${ }^{77}$ tais como João Batista ${ }^{78}$ St Antão, ${ }^{79}$ Paulo de Tebas, ${ }^{80}$ Maria Egípcia, ${ }^{81}$ San Millán, ${ }^{82}$ San Felices, ${ }^{83}$ os Monges do Egito ${ }^{84}$ e o próprio Cristo, que "...pora nos dar enxiemplo al desierto se miso...". ${ }^{85}$

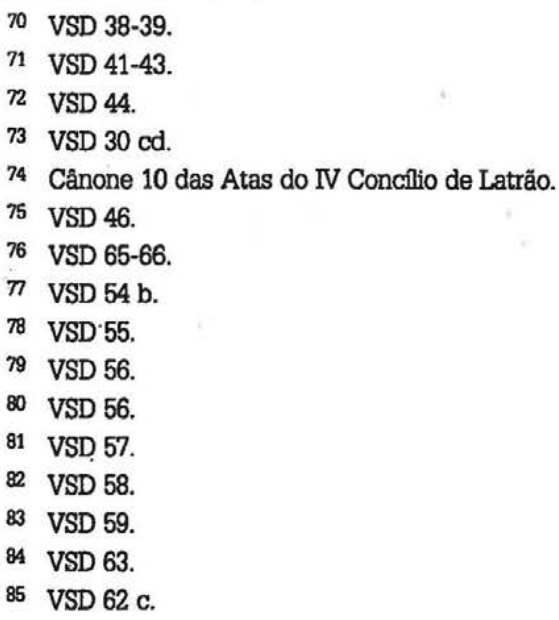


Mesmo vivendo como eremita, St Domingo não se descuidou de suas responsabilidades pastorais, que exerceu através da intercessão. Segundo as coplas de 75 a 79 , o santo orava pelos enfermos, cativos, pagãos, pela paz entre os povos e para que cessasse a heresia.

Após algum tempo como eremita, o poema relata que St Domingo decidiu ingressar na vida monástica. Esta opção foi fruto do desejo de viver de forma ainda mais severa, visto que como monge só poderia agir sob licença de seus superiores, exercendo assim a obediência. ${ }^{86}$ Como clérigo regular, o santo foi exemplar:

\footnotetext{
"Apriso bien la orden el novel cavallero,

...manso e abenido, sabroso compañero,

homilloso en fechos, en dichos verdadero. ${ }^{87}$

... lo que dicié la regla facié él toda via, guardava bien la orden, sin ninguna folia." ${ }^{88}$
}

No episódio narrado nas coplas de 126 a 181, que o autor confessa que "...me pesa mucho de coraçón...", ${ }^{89}$ onde o santo entra em conflito com o Rei Garcia de Navarra, é demonstrado o zelo pelo patrimônio eclesiástico, luta contra a intervenção secular em questões eclesiais e repúdio à simonia. O rei desejava dispor dos bens do mosteiro, porém St. Domingo resistia às suas ordens. Frente as ameaças do Rei, Berceo coloca a seguinte resposta em boca do monge:

"Puedes matar el cuerpo, la came maltraer,

mas non as en la alma, reï, ningún poder;

dizlo el evangelio que es bien de creer,

el qui las almas judga, essi es de temer. ${ }^{n 0}$

O relato ainda inclui uma crítica ao abade do mosteiro de San Millan que acatando o desejo do Rei, não só lhe entregou o que desejava como também expulsou a St. Domingo ${ }^{91}$ Este foi acolhido no reino de Castela, ${ }^{92}$ onde foi o responsável por restaurar o mosteiro de Silos..$^{93}$

Como abade, "...fo siempre casto, de bona paciencia, / umilloso e manso, amó obediencia". ${ }^{94}$ Não se descuidou do zelo para com os laicos. Preocupava-se com a saúde fisica e espiritual dos fiéis. ${ }^{95}$ Exortava a que "...quanto pudieres, guárdate de pecar...". ${ }^{96}$ Dedicava-se também à pregação. Berceo elaborou um grande sermão fictício onde o santo trata dos pecados mortais, dos dízimos e ofertas, das práticas supersticiosas, da fornicação, do arrependimento e da confissão. ${ }^{\text {r }}$

\footnotetext{
86 VSD 81-83.

87 VSD 84 acd.

88 VSD $85 \mathrm{~cd}$.

89 VSD 126.

90 VSD 153.

91 VSD 167-168.

92 VSD 182-186.

93 VSD 187-215

94 VSD $224 \mathrm{ab}$.

95 VSD 314.

96 VSD 313c.

97 VSD 463-473.
} 
Em todo o poema encontramos traços do projeto moral proposto pelo papado mesmo quando o que é narrado não se refere diretamente a St. Domingo.

Ao apresentar um breve relato sobre uma jovem reclusa no mosteiro de Silos, Ória, Berceo ressalta o valor da castidade: "...más querrié seer ciega que veerse casada" ${ }^{98}$. O autor ainda acrescenta, como uma das virtudes desta santa, "Querié oír las oras más que otros cantares, / lo que dicién los clérigos más que otros joglares..."..$^{99}$

A castidade, a pobreza e a vida longe das paixões do mundo são louvadas na obra:
"Señor, si Dios lo quiere, tal es mi voluntad, prender orden e velo, vevir en castidad, en un rencón cerrada iazer en pobredad, vevir de lo que diere por Dios la christianidad. ${ }^{100}$

Há ainda dois detalhes dignos de nota no relato de Berceo. O primeiro diz respeito à consagração da igreja de Silos realizada com a presença do legado papal Ricardo, enviado por Gregório VII ${ }^{101} \mathrm{O}$ segundo faz referência à canonização de St. Domingo, "...del papa otorgado". ${ }^{102}$

O clérigo ideal presente no relato de Berceo possui, sem dúvidas, as virtudes morais ensinadas pelo cristianismo desde a igreja primitiva. Basta nos reportarmos às epístolas paulinas que recomendam a humildade, a bondade, a pureza. Porém, St Domingo comporta-se da forma como recomenda o IV Concilio de Latrão: além de possuir uma conduta moral irrepreensivel, é instruido, cuida do patrimônio eclesiástico e zela pela fé dos laicos.

Esta correspondência entre a obra de Berceo e as atas do IV Concílio de Latrão é refletida através da semelhança semântica quanto aos termos que apresentam as ações e os adjetivos associados aos clérigos em ambos os textos. Destacamos, por exemplo, a não-participação ou assistência aos jogos; ${ }^{103}$ a obediência; ${ }^{104}$ o cuidado com livros e roupas do patrimônio eclesiástico. ${ }^{105}$

Este perfil ideal no qual se enquadra a descrição que Berceo faz de St. Domingo, constrói-se sob os mesmos princípios teológicos que fundamentam o sistema ético proposto por Roma: a negação do mundo como fruto da eleição divina e para .estar apto a exercer a liderança sob os laicos e o compromisso com a comunidade de fiéis através da ação pastoral. Ao elaborar sua Vida de $S t^{\circ}$ Domingo de Silos, Gonzalo de Berceo foi, portanto, influenciado pelos ideais morais do papado.

Berceo era clérigo, vivia no Reino de Castela, escreveu em castelhano e para castelhanos. Teria sido um caso limite? Acredito que não. $O$ fato de a igreja caste-

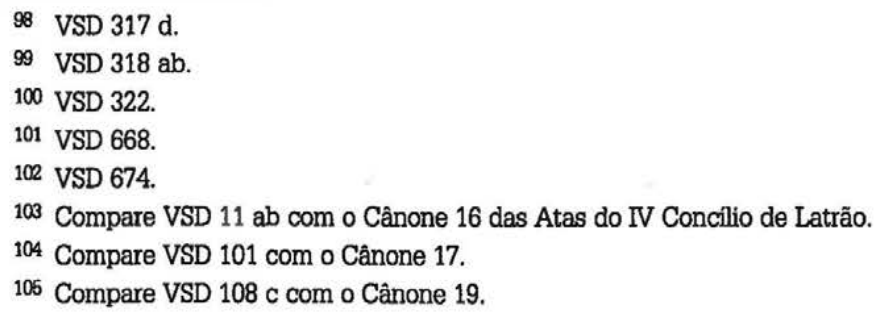


lhana manter-se resistente à soberania papal e seus prelados estarem comprometidos com os interesses reais, não anula a possibilidade de que estes ideais morais circulassem entre os seus clérigos.

Conforme assinalamos na introdução, os fenômenos ideológicos mantêm uma certa autonomia em relação às estruturas materiais. A resistência encontrada pelo papado em Castela está relacionada não somente às particularidades deste reino marcado pelo forte sentimento de Reconquista, mas pela própria natureza das estruturas políticas do Ocidente Medieval, marcadas pela fragmentação e pluralidade de poderes.

O sistema ético elaborado por Roma visava justificar e legitimar a sua preeminência sobre a hierarquia eclesiástica e os poderes seculares. Ao aspirar ao poder universal, o papado entrou em conflito com os demais poderes presentes no Ocidente. Seu poderio nunca foi, de fato, total, o que não significa que seu projeto moral não tenha se expandido e alimentado, durante toda a Baixa Idade Média, um projeto utópico de sociedade onde os clérigos perfeitos zelariam pela felicidade dos laicos. 